\title{
MARX E A FORMAÇÃO DO HOMEM ${ }^{1}$
}

\author{
Mario Alighiero Manacorda ${ }^{2}$ \\ Tradução: Newton Ramos-de-Oliveira e Paolo Nosella \\ Revisão : Paolo Nosella
}

Resumo: Este artigo traz para a discussão a grande e fecunda tradição pedagógica que há no socialismo desde início do século XIX e, particularmente, as contribuições e reflexões de Karl Marx a este respeito. Manacorda soube extrair novas conclusões que ultrapassam as proposições de formação estreitas e unilaterais dos liberais e até mesmo dos socialistas utópicos, e propôs uma educação de outro tipo, que vincula trabalho e instrução, que seja financiada pelo Estado e que resguarde a importante e necessária independência tanto das intromissões do Estado como da Igreja. Nesta perspectiva, em Marx temos a defesa de uma formação omnilateral, que integra a ciência e a técnica ao desenvolvimento do homem em todas as suas dimensões e potencialidades, bem como, dos homens todos, superando as contradições e os antagonismos de classe.

Palavras-chave: Educação socialista, omnilateralidade, educação marxista

\section{MARX AND THE FORMATION OF MAN}

\begin{abstract}
This article brings to the discussion the great and fertile pedagogic tradition that exists in the socialism from beginning of the century XIX and, particularly, the contributions and reflections of Karl Marx in this respect. Manacorda could extract new conclusions that exceed the narrow and unilateral propositions of formation of the liberals and even of the Utopian socialists, and proposed an education of another type, which links work and education, which is financed by the State and that guard the important and necessary independence so many of the interference of the State as of the Church. In this perspective, in Marx we have the defense of a formation omnilateral, what integrates the science and the technique to the development of a man in all his dimensions and potentialities, as well as, of the men all, surpassing the contradictions and the antagonisms of class.
\end{abstract}

key words: Socialist education, omnilateralidade, Marxist education

Desde o início do século XIX, há, no socialismo utópico, uma grande tradição pedagógica muito fecunda não apenas de ideias, mas também de iniciativas práticas. As ideias ampliavam aquelas proposições democráticas da revolução francesa; as iniciativas estavam in vitro, ou seja, como pequenas ilhas utópicas, ou fantasias experimentais, do tipo da Nova Harmonia de Owen, da Icária de Cabet, dos Falanstérios de Fourier, sem dúvida originais, que visavam instruir também os meninos das camadas subalternas e unir ensino e trabalho. E todas retomavam a mesma linguagem da revolução francesa, quando Talleirand, ainda não era um emblema da Restauração, apresentava à Constituinte (julho de 1789 - setembro de 1791) um projeto de lei para o "ensino público, gratuito, das partes referentes ao "ensino necessário a todos os homens". Logo se acrescentou outra dimensão: a união de ensino e trabalho, evocado no projeto jacobino Lepeletier, discutido no dia 25 de junho de 1793 pelo Comitê do Ensino da Convenção, acolhido por Robespierre e votado 
no mês de agosto seguinte, mas nunca posto em prática, que propunha uma "Educação, literária, intelectual, física, moral e industrial". Portanto, era um tema liberal-democrático associado a um tema jacobino pré-socialista, que se integraria mais tarde ao patrimônio pedagógico comum, mas que ficara típico do socialismo utópico e do socialismo em geral e até mesmo do comunismo.

Esta tradição chega às experiências do socialismo europeu e, em geral, da "escola nova" (éducation nouvelle) e, finalmente, às realizações da União Soviética e dos outros países do socialismo real com suas releituras do projeto marxista, com suas interpretações parciais ou equívocas, com reconsiderações e pesados equívocos a respeito do pensamento marxiano que muito influenciou o desenvolvimento de toda pedagogia moderna, ativa e puerocêntrica da América e da Europa, de inspiração liberal e democrática.

De toda esta tradição, a reflexão de Marx foi e permanece como um dos momentos teoricamente mais considerado e, ainda hoje estimulante, que, neste campo, soube tirar novas conclusões. Vou revisitá-la para verificar se seu entrelaçamento de temas que, para simplificar, chamarei de humanistas (liberais) e industrialistas (comunistas), pode ainda trazer estímulos à nossa realidade atual.

\subsection{Instrução e trabalho}

Os temas específicos da formação do ser humano têm uma forte presença nas reflexões de Marx, que, sem ser, felizmente, um técnico de pedagogia, foi solicitado à vida toda, em razão de sua militância política, a pronunciar-se com clara tomada de posição em documentos oficiais de grande relevo: para repetir uma de suas expressões, suas tomadas de posição referem-se tanto ao político quanto ao social, isto é, tanto à liberdade de ensino, que é um princípio liberal, quanto à união do ensino e trabalho, que é princípio socialista.

Essas suas tomadas de posição política, bem longe de ter o caráter de improvisos ocasionais, encontram plena resposta em todas as suas reflexões de 40 anos, que definimos ao mesmo tempo como sendo de caráter "filosófico" e "econômico". São expressão de suas convicções mais profundas sobre o destino do homem como indivíduo e membro da sociedade. E, como em toda sua indagação, estas reflexões também se baseiam, de igual modo, de uma parte em dado cultural (ou, se quiser, bibliográficas), isto é, na tradição da pedagogia liberal democrática e socialista que o precederam e, de outra parte, em dados econômicos concretos, ou seja, na experiência prática e legislativa que acontecia nas fábricas da Inglaterra, "demiurgo do mundo burguês. Exatamente assim: o comunista e iliberal Marx (não é assim que o pensam?) referia-se muito frequentemente aos avanços do mundo capitalista e burguês mais progressista. Esses dois momentos ou fundamentos, o político e o social, o cultural e o econômico, ou, o liberal e o socialista, devem se manter sempre presentes, quando se percorre as vicissitudes de sua reflexão sobre a temática da formação do homem.

Em 1845 já aparece em polêmica com o materialismo abstrato, um toque sobre o tema liberal do relacionamento educativo entre o indivíduo e o poder.

Na terceira Tese de Feuerbach (1845), lemos:

A doutrina materialista sobre a mudança das circunstâncias e da educação esquece que as circunstâncias são mudadas pelos homens e que o próprio educador tem que ser educado. E, por isso, deve separar a sociedade em duas partes: uma das quais se eleva sobre a outra (W.3) ${ }^{3}$.

Evidentemente, isso é parte de sua crítica à relação estado-sociedade civil de Hegel que reaparece, enriquecida pelas considerações econômicas, em suas últimas intervenções. Mas, logo virá a revolução de 1848 e suas primeiras tomadas de posição sobre o ensino 
podem nos surpreender porque contradizem uma indicação que aparecia como exigência do industrialismo e que ainda hoje é acolhida quer no mundo capitalista quer no mundo socialista. Para compreendê-la, devemos examinar dois textos que precedem ao "Manifesto", um de Engels e o outro do próprio Marx.

A primeira redação de um documento marxista que se refere ao ensino remonta ao amigo Friedrich Engels, que, em novembro de 1845, redige, em forma de "catecismo" revolucionário, os princípios do comunismo. Aí, ao responder à pergunta sobre o previsível desenvolvimento da revolução comunista, que já se anunciava iminente, propõe: "instrução de todas as crianças, a começar no primeiro momento quando podem dispensar os cuidados maternos, em instituições nacionais mantidas pela nação. Instrução e experiência de fábrica (Fabrikation) conjugadas" (W. 4, p.18, 8) ${ }^{4}$.

A primeira parte desta proposta sobre a obrigatoriedade ("todas" as crianças) e a gratuidade ("mantidas pela nação") claramente propõe medidas de caráter iluminista e jacobino; a segunda medida é de caráter socialista. Engels ilustrava este programa recorrendo às teses comentadas por ele mesmo e por Marx, naquele mesmo ano, em sua grande polêmica da "Ideologia alemã", que permaneceu inédito na época.

No parágrafo 20 desse seu Catecismo, depois de ter denunciado com as mesmas palavras desse texto a divisão do trabalho que faz "de alguém um camponês, de outro um sapateiro, de um terceiro, operário de fábrica, de um quarto, um especulador na bolsa", explicava:

O ensino permitirá aos jovens seguir todo o sistema da produção. Eliminará dos jovens o caráter unilateral impresso em todo indivíduo pela atual divisão do trabalho. Deste modo, a sociedade organizada pelo regime comunista oferecerá a seus membros ocasião para aplicar onilateralmente (allseitig) suas atitudes desenvolvidas onilateralmente (allseitig)". (idem, ibidem)

O adjetivo-advérbio allseitig, que eu sempre traduzi literalmente como "allseitig"/onilateralmente, voltará repetidamente e com força nos textos de Marx, para ilustrar de modo original aquele ideal formativo que já em Platão se apresentava - a seu modo e contra sua própria tese da unilateralidade do ser humano - como o ideal do homem completo. E projetava: "o desenvolvimento onilateral das capacidades de todos os membros da sociedade, por meio da eliminação da atual divisão do trabalho que existe até agora, através do ensino industrial (industrielle), por meio da alternância das atividades" (Referência?). Portanto, propõe um programa que vai além da hipótese liberal de um ensino diferenciado para todos e que poderia ser definido como pluriprofessional, com plena confiança no desenvolvimento da indústria, mas que, curiosamente, deixava de lado a denúncia de sua contradição. Assim, essa formulação trazia consigo um risco.

No dia 29 de novembro de 1847, Engels se encontrou com Marx no Congresso da Liga dos comunistas e lhe entregou seu Catecismo, para que lhe servisse de base para o "Manifesto", cuja redação lhe tinha sido designada pela Liga.

Mais tarde, na segunda metade de dezembro, a União dos operários de Bruxelas lhe pede duas conferências, que publicará apenas dois anos mais tarde, após o fracasso da revolução, com o título de "Trabalho assalariado e capital", nas quais desenvolve uma tese que já evidencia contraste parcial com a proposta de Engels, de quem sublinhava o caráter utópico e reformista: "Outra proposta predileta dos burgueses é o ensino, em particular o ensino industrial (industrielle) universal". Portanto, Marx critica o ensino industrial do tipo liberal apoiado por Engels, e o atribui aos burgueses. E continua: 
o verdadeiro significado que o ensino tem para os economistas filantrópicos é treinar cada trabalhador em tantos ramos de trabalho quanto possível, de modo que, se houver introdução de novas máquinas ou mudança na divisão do trabalho, e, por isso venha a ser expulso de uma fábrica, possa mais facilmente achar outra atribuição em outras fábricas. (idem, ibidem).

E quem são aqueles burgueses e aqueles economistas filantrópicos? São os socialistas utópicos à Saint-Simon, à Fourier, à Cabet e outros já contestados na "Ideologia alemã" que haviam exaltado o borboletear, isto é, o voar aqui e acolá como borboletas saboreando o pólen das flores do ensino industrial para predispor os jovens, favorecendo suas vocações, para este ou aquele tipo de trabalho exigido pela indústria. Em suma, nada mais do que uma medida à Rousseau, atualizada às exigências da indústria capitalista. Enfim, Engels, em sua proposta, havia inadvertidamente posto no mesmo saco a pluriprofissionalidade e a onilateralidade.

Talvez, Engels e Marx tenham elaborado as duas propostas, a do Catecismo e a das lições de Bruxelas sobre Trabalho assalariado e capital, nos mesmos dias, desconhecendo um o que o outro fazia. Mas, quando depois Marx redige o "Manifesto", o que acontece com aquela parte das teses, "burguesas e filantrópicas", de Engels ? Retomando-as em boa parte, ele retorna sobre as mesmas medidas imediatas que o proletariado deverá executar depois da tomada do poder (evidenciadas, seja bem claro, como "insuficientes e insustentáveis" (W. 4, p. 481): "Ensino público e gratuito para todas crianças. Abolição do trabalho em fábrica para as crianças nas condições atuais. Unificação do ensino com a produção material (mit der materiellen Produktion)" (idem, ibidem).

O que há aqui de novo, e o que já estava nas teses de Engels? Deixando de lado a simplificação das fórmulas, os termos engelsianos Fabrikation e industrielle são substituídos por materielle Produktion, e, junto com as habituais teses liberais comparece a proposta de abolir o trabalho das crianças em fábrica "em sua forma atual", aspecto estranhamente esquecido por Engels que entretanto havia escrito um polêmico e humanitário livro sobre "A situação da classe operária na Inglaterra". Portanto, dentro da prospectiva fundamental da união de ensino e trabalho, também Marx é favorável ao envolvimento, já existente fazia algum tempo, mas, em forma desumana e sem qualquer tutela, das crianças no sistema de produção da época, desde que, entretanto, limitado e associado ao ensino deles. Por outro lado, adverte que a fábrica por si mesma não supera a divisão do trabalho que empobrece o homem, portanto, precisa de intervenção.

Compreende-se bem sua coerência entre a recusa do ensino profissional universal e a confirmação da união de ensino e produção material, mas exclui todo adestramento (treino) subalterno à produção e projeta uma formação do homem completo.

\subsection{Uma tríplice formação para a onilateralidade}

Sobre este tema da união de ensino e trabalho, já presente nas reflexões sobre a Ideologia Alemã e lembrado por Engels, Marx voltará com contínuos aprofundamentos em toda sua reflexão que faz a partir daí. Trata-se do pleno desenvolvimento do ser humano: que não seja ou sapateiro ou filósofo, mas ambos e algo mais "onilateralmente".

Duas décadas após o Manifesto, ele retorna aos temas do ensino em outra importante ocasião política. Em agosto de 1866, sem poder participar em Genebra dos trabalhos do I Congresso da Associação Internacional dos trabalhadores por estar ocupado com a revisão definitiva do primeiro volume do "Capital", cujo manuscrito tinha prometido entregar ao editor alemão no outubro seguinte, redigiu algumas Instruções aos 
delegados de seu partido, das quais nos resta um texto em inglês (publicado pelo "The International Courier" nos dias 20 de fevereiro e 13 de março de 1867) e um exemplar em alemão (no "Vorbote" números 10 e 11 de outubro de 1866). Infelizmente, dessas duas redações nasce um pequeno problema a respeito do significado exato do termo "politécnico", cuja compreensão é fundamental para o pensamento de Marx.

No Ponto 4, com o título Trabalho dos adolescentes e das crianças (de ambos os sexos)", declarava:

Por ensino entendemos três coisas: primeira, formação intelectual (geistige Bildung); segunda, educação física (körporliche Ausbildung), como é ensinada em escolas de educação física e por exercícios militares; terceira, ensino ou adestramento politécnico (polytechnische Erziehung) que transmita os fundamentos científicos gerais de todos os processos de produção e que, ao mesmo tempo, introduza a criança e o adolescente no uso e na capacitação de manejar os instrumentos elementares de todas as profissões (W.16, p. 194-195)5.

E mais: ao ilustrar os objetivos deste tríplice ensino para todos:

Com a subdivisão das crianças e dos adolescentes dos 9 aos 17 anos em três classes, é necessário anexar um programa gradual e progressivo de instrução intelectual, educação física e politécnica. A união de trabalho produtivo remunerado, formação intelectual, exercício (Übung) físico e adestramento (Abrichtung) politécnico alçará a classe operária a um plano superior ao das classes superiores e médias. Nem os agentes e nem os genitores podem ser autorizados a explorar o trabalho juvenil, nem mesmo quando conjugado ao ensino. (idem, ibidem).

Qual é o sentido de sua tríplice proposta que será acolhida pela Internacional, mas cuja palavra-chave, "politécnico", precisa ser explicada? Como essa proposta se reporta às reflexões do "Manifesto? Enquanto o ensino será melhor definido como ensino intelectual, junto com a produção material, acrescenta-se, como novo momento, a educação física. E, se Marx não especifica o que entende por instrução intelectual, parece assim que mais ou menos aceite o sentido tradicional; referindo-se por ginástica a todas as escolas de ginástica e aos exercícios militares, tendo, com certeza, em mente, o desenvolvimento do esporte nos colégios ingleses e a tradição alemã das "turnplätze" (mudanças de lugar, dos espaços para o método de ginástica Karl Ludwig Jahn); para compreendermos o significado exato do adestramento ou ensino politécnico temos que recorrer às reflexões do "Capital", em cuja redação definitiva - lembre-se - Marx trabalhava justamente naqueles dias.

Nessa obra, Marx, escrevendo obviamente em alemão, não usará o termo "politécnico", que corre o risco de identificar sua proposta com a "instrução industrial universal", isto é, pluriprofissional, preferida pelos burgueses e pelos economistas filantrópicos, que Engels propôs em 1847; utilizará, em vez disso, inequivocamente, a expressão "ensino tecnológico de teoria e prática".

O que significa esta aparentemente pequena diferença de termos, de politécnico a tecnológico? Significa que, com maior clareza do que no "Manifesto", Marx não entende uma instrução profissional pensada para os fins imediatos da indústria, como proposta de um ensino subalterno para as camadas populares, distinta daquela desinteressada para as camadas superiores, mas tem em mente algo diferente e mais humano: ensino formativo, 
cultural, entendido como união da ciência e da técnica, aos fins do homem, para todos os seres humanos, sem distinção de classe.

Para uma compreensão mais exata do valor dessas teses, considere-se que estão inseridas no capítulo X, no centro do "Capital", onde se reconstrói o desenvolvimento histórico (que já tínhamos apontado ao falarmos da divisão do trabalho): da pequena oficina de artesanato, passa-se inicialmente pelos ofícios que reagrupam os artesões que mantêm suas funções limitadas, mas em si completas de ciência e trabalho manual, daí às primeiras fábricas fundadas na divisão do trabalho que despojam as profissões artesanais de sua ciência e, por fim, à fábrica mecanizada que subordina totalmente o operário como acessório da máquina. Pois bem, neste ponto insere-se a reflexão sobre a relação entre "a moderníssima ciência da tecnologia" e a educação.

Eu supunha, até agora ainda creio com razão, que essas páginas tenham sido sugeridas justamente pela necessidade de ter que enfrentar os problemas da educação para o II Congresso da Internacional e que deva tê-las inserido no grande livro por ocasião da última revisão do texto. Aqui, Marx novamente propõe a tríade educativa já indicada nas Instruções aos delegados e, apontando para uma realidade existente no mundo industrial, recorda que tanto a legislação inglesa sobre as fábricas quanto a ação filantrópica de Owen demonstraram "a possibilidade de coligar o ensino e a ginástica com o trabalho manual e, portanto, também o trabalho manual com o ensino e a ginástica" (idem, ibidem).

Não é pouca coisa, porque mostra que se trata não de uma construção ideológica de seu cérebro utópico, mas de uma realidade que ele já entrevê atuante. E, o retornar da frase sobre si mesma, passando primeiro da instrução ao trabalho e depois do trabalho à instrução, não é um jogo de palavras, mas indica que isto vale para todos, ou seja, tanto faz que se parta de uma exigência manual ou técnica para as pessoas cultas, quanto que se parta de uma exigência cultural para os que são destinados ao trabalho industrial, porque todos devem ser preparados juntos a pensar e atuar, que aliás, é tema antigo em sua reflexão. E para tal fim, precisa de uma educação que incorpore instrução tecnológica, teórica e prática, finalmente total, do homem realmente completo, não mais, platonicamente voltada só para completar a formação cultural, mas, para todas as formas da atividade humana, visando o homem onilateral.

Este é o destino do homem e para isso deve visar o ensino intelectual, físico e tecnológico para todos. Porque, divisão dos homens entre os destinados ao trabalho e outros à ciência, os à produção e outros ao consumo, uns ao cansaço ou outros ao gozo, é o nó das contradições da sociedade capitalista que Marx pretende cortar. Eis "o germe da educação do futuro"'.

\subsection{9: o entrelaçamento de temas comunistas e liberais}

Até este ponto, ao falar da tradição pedagógica comunista, encontramos os temas tipicamente comunistas da relação entre ensino e trabalho. Agora os encontraremos plenamente entrelaçados com os temas liberais da relação entre ensino e liberdade, ambos presentes em Marx em plena sintonia com o ideário do liberalismo.

Nos dias 10 e 17 de agosto de 1869, três anos depois do I Congresso da Internacional, para o qual tinha elaborado suas "Instruções aos Delegados", e dois anos após a publicação do "Capital", Marx participa dos trabalhos do Conselho Geral, com duas intervenções orais das quais nos restam, porem, apenas atas estenografadas em inglês (que a edição germânica dá em alemão). Não obstante a esquematização de sua redação são bem claras para testemunhar indubitavelmente seu pensamento.

Quanto à relação instrução-trabalho, há, preliminarmente, uma breve declaração de 10 de agosto em que ele declara: "Pelo que se refere à circunstância que as crianças não 
deveriam ser introduzidas no trabalho, uma coisa é certa: isto não traria a diminuição dos salários e as pessoas se habituariam" (W. 16, p. 563). O trabalho de fábrica é uma realidade mesmo que as pessoas ainda não estivessem habituadas. Para Marx, realista e não utópico, isso contribui para o desenvolvimento completo de uma personalidade capaz de operar com o pensamento e com as mãos, ou seja, de associar cultura e trabalho. Na realidade, depois dele, a história caminhou numa direção diferente, mas, apenas no mundo desenvolvido. Mais tarde, no dia 17 de agosto, tratando mais quanto ao mérito, volta a esclarecer a distinção entre o ensino tecnológico propugnado por ele e o ensino técnico dos burgueses:

A formação tecnológica (technological: agora também em inglês), recomendada por autores proletários, deve compensar as lacunas que surgem da divisão do trabalho. Mas sempre se partiu do que a burguesia entende por ensino técnico (technical) e, por consequência, incorremos numa interpretação errada (W. 16, p. 563).

Aqui é bem clara a diferença entre o técnico e o tecnológico e, após confirmada a decisão do Congresso de Genebra sobre a união do ensino e o trabalho, é uma confirmação de tudo que declaramos até agora do trabalho na fábrica também para as crianças, desde que regulamentado e associado ao ensino formativo.

Nos temas liberais, ou melhor, democráticos, é óbvia por parte dele a declaração de que: "O Congresso pode decidir sem hesitação que o ensino escolar deve ser obrigatório". E já sabemos que, quanto à questão se o ensino deve ser estatal ou privado, ele responde partindo da distinção eminentemente liberal entre Estado e governo, e explica que "o ensino pode ser estatal sem estar sob o controle do governo". E, para esclarecer, cita o exemplo dos Estados Unidos onde "toda municipalidade tem que garantir a todos um ensino escolar elementar", enquanto, para corrigir o caráter regionalista, "foi proposto um controle central". Portanto, a união de iniciativa local combinada com o controle estatal. E insiste explicando que a tarefa do governo "é vigiar sobre o respeito à lei, sem o direito de imiscuir-se no ensino real e próprio, exatamente como os inspetores de fábrica que vigiam o cumprimento das leis sobre as fábricas" (W.16, p.563). Em suma, como sempre, aprecia o sistema liberal-democrático em uso nos Estados Unidos. (Podemos recordar que nesses anos Marx vinha assiduamente colaborando com a imprensa socialista dos EUA).

Mais tarde, na sessão do dia 17 de agosto do Conselho da Internacional, com base na intervenção da senhora Herriet Law de usar os bens da Igreja para as necessidades do ensino geral, ele propõe que o Congresso se pronuncie também contra a Igreja (W, 16, p.563). Anti-estatal portanto, como sabemos, e laicista. E continua, com maior empenho, sua tomada de posição quanto à proposta do cidadão Milner de ministrar "nas escolas que já existem, conhecimentos de economia". Sua resposta é tão ultra-liberal que espanta: defende que tais noções os jovens devem receber das experiências da vida cotidiana, porque, mais do que à escola cabe aos adultos ensiná-las. E acrescenta:

nem na escola elementar nem nas escolas superiores deveriam introduzir matérias que admitem interpretações de partido ou de classe. Só matérias como ciências naturais, gramática etc. podem ser ensinadas na escola. As regras gramaticais, por exemplo, não se modificam se são ensinadas por um crente tory ou por um livre pensador (idem, ibidem)

E, para evitar equívocos, repete: "matérias que admitem conclusões diferentes não devem ser ensinadas nas escolas; dessas podem ocupar-se os adultos sob a direção dos 
mestres como a senhora Law, que dava lições de religião". (W. 16, p.564). Como se pode observar, a economia é considerada por ele entre as matérias que admitem interpretações de partido ou de classe: há talvez necessidade de comentar que esta é uma confirmação de sua consciência de ter elaborado uma economia política crítica em contraposição à economia política crítica clássica, isto é, que também a economia não é uma ciência exata?

Evidentemente, a forma estenográfica das anotações acentua a peremptoriedade das expressões, mas sua essência é certa: o Estado e, mais ainda o governo, não deve intervir na prática do ensino e devem ser banidas também as interpretações ideológicas "de partido ou de classe". Eis uma atitude laica e liberal, até hiper-liberal, talvez com um excesso de utopismo porque, antes de tudo, onde está na realidade o limite entre o que é opinião e o que é universalmente aceito pelas ciências, não apenas do homem, mas também da natureza? E, ainda, o que é a liberdade de ensino, que hoje é para nós tão importante? Será que Marx temia algo nesse ponto? A esta pergunta me limitarei a responder apenas que, descartada como insustentável uma hipótese de um ensino apenas de conteúdos absolutamente indiscutíveis (pense só no debate americano de hoje sobre o darwinismo, ou no espaço oferecido para um ensino católico em escola italiana, fundada sobre a liberdade de ensino), a liberdade dos docentes, sempre de difícil controle, pode entrar em conflito com outra liberdade básica, a liberdade de aprendizagem dos alunos. É o difícil desafio dos dias atuais. Seja como for, Marx antepõe a estas suas reflexões uma consideração mais geral que define os âmbitos:

A esta questão está ligada uma dificuldade de um tipo especial. Por um lado, se requer uma mudança das condições sociais para criar um sistema de ensino correspondente e, por outro lado, se requer um sistema escolar correspondente para poder alterar as condições sociais. Por isso é preciso partir da situação existente (W. 16, p 562).

Esta é uma observação que precisamos guardar na memória.

É certo, seja como for, que estas posições de Marx podem ser acusadas de tudo, menos de serem antiliberais: pelo contrário, até demonstram um excesso de liberalismo.

\subsection{5: temas ainda comunistas e liberais}

Seis anos mais tarde, no início de maio de 1875, Marx comenta na "Crítica do programa de Gotha" as teses do Partido Social Democrático alemão, dirigido por Lassale, sobre o ensino (já nos referimos a isso ao falarmos do Estado.)

Ali, ele volta a enfrentar os dois temas, da relação ensino-trabalho e da liberdade de ensino, e, mais uma vez, algumas afirmações peremptórias, ligadas às condições sociais existentes e ao mesmo tempo, projetadas ao futuro, precisam de um comentário.

Sobre os temas liberais, suas declarações podem ainda ser mais surpreendentes.

Educação popular (Volkserziehung) é igual para todos? O que se pode imaginar com tais palavras? Acredita-se talvez que na sociedade de hoje (e só se trata dessa) a educação possa ser igual para todas as classes sociais? Ou está se querendo que até as classes superiores devem ser forçadamente reduzidas àquela modesta instrução - a escola popular que só é compatível com as condições econômicas não apenas dos trabalhadores assalariados, mas também dos camponeses? (W.19. p.30 ${ }^{6}$.

E ainda, sempre permanecendo no existente, ao comentar a declaração socialdemocrata que propunha: "ensino geral obrigatório, ensino gratuito", ele pede que se 
proponha também o enriquecimento dos conteúdos tecno-científicos na escola popular: " $\mathrm{O}$ parágrafo sobre escola deveria, pelo menos, ter pretendido escolas técnicas (teórica e prática) acopladas à escola popular (elementar: Volkschule)". E aqui, me parece, que, não se fala de "tecnológico", mas apenas de técnico, isso acontece apenas porque está discutindo o programa social-democrático de aplicação imediata, mas, o entre parênteses "teóricos e práticos" nos remete sem dúvida à exigência que antes tinha expressado ao falar de "tecnológico".

Mais indubitável, sem dúvida alguma, evidencia-se sua posição sobre o Estado quando, ao confrontar novamente a temática da liberdade de ensino, a retoma quase que com as mesmas palavras liberais que já tinha utilizado em 1869. De fato, declara:

deve-se absolutamente recusar a ideia (proposta pelo programa socialdemocrático) de uma educação do povo gerida (ministrada) pelo Estado. Determinar, com uma lei geral, os recursos das escolas populares, a qualificação do pessoal que ensina, os ramos de um ensino etc. e, como acontece nos Estados Unidos, supervisionar por meio de inspetores do Estado o cumprimento dessas prescrições legais é algo totalmente diferente de efetivar o Estado como o educador do povo! Ao contrário: o que se deve igualmente excluir governo e igreja de qualquer influência sobre a escola (W. 19, p.30).

E podemos recordar (como tínhamos anunciado) a advertência da III Tese de Feuerbach de que "o educador deve ser educado". Novamente, o que pode ser mais liberal?

A força de Marx é de ter fundamentado todos esses ideais liberais e comunistas, não sobre um desejo abstrato do dever ser, como acontece com todos os fundadores idealistas do liberalismo, mas pela constatação de um poder ser; não a partir da moral, mas da realidade efetiva, e, portanto, pelos progressos da história, seja na produção da vida material, seja na organização da vida espiritual, cultural, política, como um possível desenvolvimento racional da história da humanidade em seu caminho pleno de contrastes.

Quanto ao fato de suas conclusões estarem indissoluvelmente ligadas à experiência de seu tempo e quanto ao fato de, ainda hoje, à distância de um século e meio, durante o qual o mundo muito progrediu no bem e no mal, essas conclusões possam trazer elementos úteis à compreensão e à solução de nossos problemas, é questão que ainda analisaremos. $\mathrm{O}$ certo é que, seja como for, todas as reflexões que tenham profundamente marcado a vida do seu tempo, constituem um ktema eis aei, "uma posse eterna" para a humanidade futura desde que ela saiba bem usar, o que nem sempre ocorre. 


\section{NOTAS BIBLIOGRÁFICAS}

\section{Textos de Karl Marx}

As citações de Marx são todas, por homogeneidade, da edição alemã dos Marx-Engels: Werke, Berlin, 1956-1966, indicada simplesmente com W e com os números sucessivos do volume e da página: EB. Ergänzungs Band (volume suplementar) remete aos dois volumes que integram os Gr., edição separada, de 1964, dos Grundrisse, a saber, os Fundamentos da economia política.

Em especial, os volumes aqui elencados das Werke (obras) contêm os escritos de Marx (e Engels) de onde são retiradas as citações referenciadas abaixo.

\footnotetext{
${ }^{1}$ Este texto é o quarto capítulo de um livro, ainda inédito, Marx e a Liberdade (título provisório).

${ }^{2}$ Nascido em Roma, em 9 de dezembro de 1914, formou-se em Letras na Universidade de Pisa, onde também fez Pedagogia. Foi professor em liceus e institutos de magistério, tradutor e estudioso de literários e históricopolíticos, diretor da Edições Rinascita, colaborador de jornais e revistas como Rinascita, Società, Il Contemporaneo, Rassegna Sovietica, Studi Storici, Ulisses, Il Calendário Del Popolo e revistas pedagógicas como Voce della scuola democratica, Scuola e Constitucione e Reforma della scuola. Foi membro da Associação de Defesa e Desenvolvimento da Escola Pública Italiana e integrante da seção pedagógica do Instituto Gramsci e da Comissão Cultural do Partido Comunista Italiano, além de ter participado de todas as lutas educacionais da segunda metade do século XX.

${ }^{3}$ W. 3 - Teses su Feuerbach; A Ideologia alemã.

${ }^{4}$ W.4 - Fr. Engels, I principi del comunismo; K. Marx, Il manifesto dei comunisti.

${ }^{5} \mathrm{~W} .16$ - Indirizzo inaugurale e Statuti generali dell'Associazione internazionale dei lavoratori.

${ }^{6}$ W.19 - Crítica del programma di Gotha.
} 